\title{
A RECIPROCIDADE ENTRE ESTRUTURA (ORGANIZACIONAL) E OS AGENTES (LÍDERES E LIDERADOS): UM ESTUDO SOBRE LIDERANÇA RELACIONAL A PARTIR DA TEORIA DA ESTRUTURAÇÃO DE GIDDENS
}

The reciprocity between (organizational) structure and the agents (leaders and followers): a study on relational leadership from Giddens structuration theory

\section{Gustavo Simão Lima}

Doutor em Administração pelo PPGA da PUC Minas email:EMBRAPAgsimao@gmail.com

\section{Antonio Carvalho Neto}

Doutor em Administração pela UFMG. PUC Minas

emal:carvalhoneto@pucminas.br

\section{Marcelo Simão Lima}

Doutorando em Administração pelo PPGA da PUC Minas. PUC Minas email:msl.01@hotmail.com

\section{Fernanda Versiani}

Doutora em Administração pelo PPGA da PUC Minas. PUC Minas email:nandaversiani@gmail.com

\section{RESUMO}

Este artigo analisa as influências recíprocas da estrutura organizacional nos líderes e nos liderados e destes enquanto agentes na estrutura organizacional, levando em consideração os construtos das Teorias da Estruturação de Giddens e da Liderança Relacional. O referencial teórico destaca os construtos da Teoria da Estruturação (ações não premeditadas; recursividade entre ação humana e estrutura social; dualidade da estrutura; rotinas e regras) e da liderança relacional (que mais se aproxima da Teoria da Estruturação). Trata-se de uma pesquisa qualitativa que realizou entrevistas semiestruturadas com todos os 32 empregados de empresa do setor de infraestrutura. Os resultados indicam que a organização mudou devido à influência recíproca entre agente (líder-liderado) e estrutura (organização), como em Giddens e também de acordo com os pressupostos da liderança relacional, resultante das capacidades de: provocar mudanças; utilizar regras e recursos disponíveis; enfrentar consequências não premeditadas. Este artigo contribui com lacuna na literatura de liderança ao recorrer à Teoria da Estruturação.

Palavras-chave: Liderança Relacional; Teoria da Estruturação; Recursividade; Organização-líderes-liderados.

\section{ABSTRACT}

This study aims to analyze the reciprocal influence among the organizational structure, leaders and followers, these as agents in relation to the structure, according to Giddens structuration theory and relational leadership theory. The theoretical framework highlights the four constructs of structuration theory (un/ premeditated actions; recursiveness between human action and social structure; structure duality; routines and rules) and relational leadership (the one that most closely approximates structuration theory). Qualitative research performed semi-structured interviews with all 32 employees of a company in the infrastructure sector. Results show that the success of the organization was due to the reciprocal influence of leader-follower-structure, both in Giddens and in relational leadership, resulting from the capacities to: bring about change; use available rules and resources; face unintended consequences; treat each individual as possessing a single entity. This article contributes with a gap in the literature of leadership when resorting to the theory of structuring.

Keywords: Relational Leadership; Structuration Theory; Recursiveness; Organization-leaders-followers. 


\section{INTRODUÇÃO}

A temática da liderança já conta com mais de um século de pesquisas científicas a partir de diferentes perspectivas e abordagens (DAY et al., 2014). As grandes organizações têm concentrado suas atenções em programas de formação e preparação de líderes futuros como forma de obter vantagem competitiva em um cenário globalizado (SWEENEY; CLARKE; HIGGS, 2018).

Esses programas são baseados em teorias de liderança clássicas - como a teoria Comportamental e a Teoria Situacional/Contingencial -, bem como em teorias da nova liderança (CARVALHO NETO; TANURE; MOTA-SANTOS; LIMA, 2012) - como a transacional e a transformacional. Eles têm sido formulados e disseminados pelo nível gerencial estratégico das organizações como forma de garantir maior êxito no "ensino" da sensibilidade e do know how, a fim de que esses novos líderes sejam capazes de aproveitar oportunidades e de desenvolver estratégias empresariais de abrangência global (ANDERSON; BAUR; GRIFFITH; BUCKLEY, 2017).

Porém, estas teorias nas quais são baseados estes programas baseiam-se no líder, não levando em consideração como sujeito de pesquisa outro agente fundamental da liderança: o liderado (UHL-BIEN et al., 2014; VERSIANI; CAEIRO; CARVALHO NETO, 2017). Levam em conta ainda menos a influência que a estrutura organizacional tem sobre líderes e liderados e vice-versa, como é o propósito deste artigo.

A Teoria LMX, que pode ser considerada precursora da Teoria Relacional (UHL-BIEN, 2006), é a única que foca igualmente na relação entre líderes e liderados. A Teoria Relacional vai adiante, pois além de salientar esta relação líder-liderado, considera a influência da organização (estrutura).

Por isso, entende-se que o fenômeno da liderança relacional pode influenciar na relação entre os agentes, tendo uma conexão com a Teoria da Estruturação. Ambas defendem a premissa de que a organização (estrutura) é baseada em relações complexas e contínuas entre os agentes - líderes e liderados - que se modificam recursivamente ao longo do tempo, segundo Giddens, configurando-se como um processo social (GIDDENS, 2005; UHI-BIEN et al., 2006; 2014; SANT'ANNA, et al., 2017).

Dessa forma, o objetivo deste artigo é analisar as influências da estrutura organizacional nos líderes e nos liderados e a influência destes, enquanto agentes, na estrutura organizacional. Esta análise leva em consideração os construtos da Teoria da Estruturação de Giddens.

O caráter inovador deste estudo está em considerar tanto os agentes (o líder e o liderado) quanto a situação (a estrutura organizacional). Aqui, portanto, o foco é na influência recíproca e recursiva entre os agentes e a estrutura ao longo do tempo, numa perspectiva sustentada na Teoria da Estruturação de Giddens (2003).

Cabe ressaltar que este artigo apoiou-se nos quatro construtos da Teoria da Estruturação composta por Giddens: a compreensão de ações premeditadas e não premeditadas conforme exposto acima, a natureza da recursividade entre ação humana e estrutura social, a dualidade da estrutura e as rotinas e regras (GIDDENS, 2003; 2005).

A partir disso, entende-se como premissa que as ações realizadas pelos agentes em suas vidas cotidianas são baseadas numa finalidade, numa ação social visada, carregada de consequências previstas e não previstas, ou premeditadas e não premeditadas. Quando as ações não premeditadas são ignoradas, retarda-se o conhecimento de novos arranjos e o amadurecimento do campo de pesquisa. Porém, considerando-se a nova sociologia (GIDDENS, 2003), com agentes sociais mais complexos (tratados teoricamente de maneira menos isolada, mais inter-relacionados), pode ser que analisar apenas as consequências premeditadas não seja o caminho mais adequado. Em vez disso, seria mais interessante compreender que a incidência de reações premeditadas e não premeditadas representam o "todo" de uma ação e, portanto, ambas devem ter atenção semelhante no estudo. Afinal, consequências não previstas também podem ser decisivas na perpetuação ou não da forma como se aborda o fenômeno da liderança. 


\section{BREVE SÍNTESE DA TEORIA DA ESTRUTURAÇÃO PROPOSTA POR GIDDENS}

Giddens (2003) aponta quatro elementos básicos que norteiam a Teoria da Estruturação e formam o caminho para preencher a lacuna entre a ação orientada pela estrutura e a ação construída pelos próprios sujeitos (os agentes, líderes e liderados) - para Giddens (2003), é o equilíbrio entre essas ações que rege a vida social. Os quatro elementos básicos são: as consequências não premeditadas; a recursividade; a dualidade da estrutura; e as rotinas e regras. Todos esses elementos estão intrinsecamente relacionados, o que torna difícil o isolamento analítico para apreciação individual. Cada um desses elementos impacta os demais e é novamente impactado, criando-se assim a dinâmica correspondente à Teoria da Estruturação.

Para compreender o que Giddens (2003) denomina de consequências não premeditadas, é preciso entender o conceito de "agente" e de "agência". De modo geral, Giddens (2009) coloca que o conceito de agente está relacionado com uma sequência de noções, intitulada de modelo de estratificação do agente, conforme a figura 1 :

Figura 1 Modelo de estratificação do agente

Condições não

reconhecidas da ação

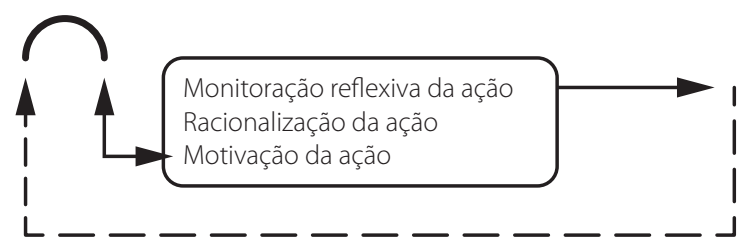

Consequências

impremeditadas da ação

Fonte: Elaborada pelos autores, adaptado de Giddens, A. (2003).

Os elementos representados pela Figura 1 são interdependentes, não existem isoladamente. $\mathrm{O}$ modelo coloca a motivação da ação como o ponto de partida da agência. Essa, por sua vez, está vinculada tanto a fatores conscientes quanto inconscientes. A motivação está associada ao potencial para a ação, um degrau anterior ao modo como a ação é cronicamente executada no tempo-espaço.

A racionalização da ação refere-se ao fato de que agir de forma social não é simples ato mecânico, pelo contrário, pressupõe racionalidade, um objetivo visado para o desempenho de alguma atividade. Isso implica a capacidade que os agentes têm de compreender por que agem de determinada forma para conseguir algo que foi estabelecido a partir de determinado motivo (GIDDENS, 2009).

A monitoração reflexiva da ação está relacionada à capacidade que o agente tem de ser sujeito e objeto de sua própria vida. Isso quer dizer que, ao mesmo tempo em que ele é agente (sujeito), ele também consegue refletir e entender sobre os desdobramentos de suas ações na sociedade e nos outros agentes (objeto). Nesse sentido, e em complementação ao argumento do elemento anterior - racionalidade da ação -, o agente sempre age com uma intenção, um objetivo visado, embasado numa racionalidade que ele consegue elaborar de forma discursiva. Assim, os agentes monitoram e ajustam frequentemente o fluxo de suas atividades e esperam que outros agentes façam o mesmo de forma autônoma (GIDDENS, 2009).

A questão que Giddens (2003) apresenta e que é essencial para a compreensão da Teoria da Estruturação é que, mesmo o agente tendo como elemento fundamental de sua ação a racionalidade e a reflexividade, ambas não são suficientes para apreender todos os aspectos da realidade. Isso quer dizer que a cognoscitividade humana é limitada e que, portanto, no fluxo da ação do agente surgem consequências que este não conseguiu prever (PERES; PEREIRA, 2014). São essas as denominadas consequências não premeditadas, que podem sistematicamente se realimentar de forma a constituírem novas condições não reconhecidas de novos atos (GIDDENS, 2009).

Giddens (2009) define a cognoscitividade como tudo aquilo que os agentes sabem e acreditam saber sobre os desdobramentos de suas ações e sobre o 
desdobramento das ações de outros agentes, tanto de maneira tácita quanto de maneira discursiva, explícita.

No âmbito da recursividade, da interação entre as esferas estruturais e humanas, surge como um desdobramento o que Giddens chama de análise de um cenário complexo a partir da análise de dois elementos fundamentais: as consequências antecipadas de uma determinada ação, o que equivale aos resultados que os agentes pretendiam obter ao empreenderem essa ação, ou seja, as suas intenções iniciais - por exemplo, a "implantação" de um determinado modelo de liderança, com metas e objetivos pré-definidos ; as consequências não-antecipadas das ações sociais, chamadas de consequências impremeditadas, ou não premeditadas, que podem ser entendidas como as consequências ocorridas e não-previstas, ou não-esperadas, de ações individuais ou coletivas decorrentes de ações intencionais ou não-intencionais, passíveis ou não de previsão, que podem, uma vez ocorridas, ser avaliadas como "positivas" ou "negativas", conforme a perspectiva do observador. Isso quer dizer que, numa perspectiva de relação social em que estão envolvidos líderes e liderados, há sempre ações vindas de um lado e de outro que, nesse fluxo de ação, criam e disseminam resultados não intencionais de conduta destes agentes. Estes resultados podem estar, muitas vezes, dissociados do planejamento inicial (do previsto) das ações e do modelo de liderança na organização.

O terceiro e o quarto elementos básicos colocados por Giddens (2009) como centrais para a Teoria da Estruturação são: a dualidade da estrutura; as rotinas e regras. A dualidade da estrutura parte da ideia de que toda ação social presume a ação do agente, pois a "estrutura" - reprodução de sistemas sociais, ou seja, relações reproduzidas entre atores ou coletividades, organizadas como práticas sociais regulares - depende de regularidades do comportamento humano. $\mathrm{O}$ fato de um agente utilizar uma determinada estrutura social contribui para a própria existência e legitimidade dessa estrutura.

O elo principal para explicar tanto a recursividade quanto a dualidade da estrutura reside nas regras e rotinas. A estrutura (organização) depende de regularidades do comportamento humano, ou seja, de que os agentes (líder e liderado) se sujeitem a regras e recursos para se expressar. Esse "sujeitar" normaliza seu comportamento e suas práticas. Assim, como a estrutura geralmente se apoia nas regras formais e discursivas, a monitoração reflexiva da ação se apoia nas regras sedimentadas no tempo e no espaço, tácitas, ainda mais poderosas que as discursivas no intuito de regular a ação dos agentes (líder e liderado).

Dessa forma, a Teoria da Estruturação prevê que as ações dos agentes sejam dotadas de consciência e intencionalidade. Contudo, os agentes não têm domínio total das condições que implicam as consequências de seus atos, já que algumas dessas consequências não podem ser previstas. Então, a história, erguida pelas atividades intencionais dos indivíduos, não é fruto apenas das atitudes premeditadas, mas também do resultado do desejo de buscar uma direção consciente para as ações, ainda que as consequências de uma determinada ação possam não ser aquilo que se intencionou originalmente (GIDDENS, 2003).

Esse ponto da teoria de Giddens pode ser muito relevante para os estudos sobre liderança, uma vez que permite analisar a maneira como o construto tem se desenvolvido e que, de forma não premeditada, tem chegado a novas condições de análises. Pois baseia-se na recursividade, sendo então fundamental para uma análise de relação de mão dupla entre líder- liderado e estrutura organizacional presentes na abordagem da liderança relacional.

\section{LIDERANÇA ENQUANTO UM FENÔMEŅO RELACIONAL}

Inúmeras são as teorias e várias são as abordagens que permeiam o fenômeno da liderança, a começar pelas abordagens tradicionais: a abordagem da personalidade (SADLER, 2003), a comportamental (BLAKE; MOUTON, 1978) e a situacional-contingencial (HERSEY; BLANCHARD, 1974).

A partir de 1970, com o surgimento da Teoria da Liderança Relacional (UHL-BIEN, 2006; 2012; 2014), muitos pesquisadores questionaram estas abordagens tradicionais, uma vez que elas não traziam como o cerne da discussão a relação entre líder e liderado, como já salientado na introdução deste artigo.

Há várias teorias na abordagem da nova liderança, que podem ser destacadas como as teorias mais referenciadas na literatura (TURANO e CAVAZOT- 
TE, 2016): transacional e transformacional (BURNS, 1978; BASS, 1985; BASS; AVOLIO, 2004; BASS, 2008), autêntica (LUTHANS; AVOLIO, 2003; YUKL, 2006), carismática (HOUSE, 1977; CONGER; KANUNGO, 1987; SHAMIR; HOUSE; ARTHUR, 1993) e Teoria Leader-Member Exchange - LMX (DANSEREAU; GRAEN; HAGA, 1975; GRAEN; UHL-BIEN, 1995). Destas, somente a Teoria LMX trata o liderado como sujeito de pesquisa, como destacado anteriormente.

Surgem novas formas de se compreender a liderança e este construto passa a ser estudado de forma a contribuir com novas perspectivas dentro da abordagem da nova liderança (SWEENEY; CLARKE; HIGGS, 2018). É o caso da liderança relacional, discutida por Uhl-bien (2006), uma das autoras que desenvolveu também a Teoria LMX. Portanto, cabe salientar a Teoria LMX como uma espécie de precursora da liderança relacional, adotada por este artigo.

Resumidamente, a Teoria LMX iniciou-se com um movimento descrito como Vertical Dyad Linkage, ou relação vertical diádica, desenvolvida por Dansereau, Graen e Haga (1975), para depois evoluir para a terminologia LMX (GRAEN; UHL-BIEN, 1995). A teoria vertical diádica trata do relacionamento entre líder e liderados, com duas possibilidades de ligação: exogrupo ou out-group (grupo de fora); endogrupo ou in-group (grupo de dentro). A primeira propicia um relacionamento mais distante, de baixa qualidade, entre líder e liderado. Pode-se dizer que a relação entre eles é formal (pode acontecer a partir dentro ou de fora da organização). A segunda vai além do contrato de trabalho formal, trata-se de uma relação de confiança e respeito. Esta relação é baseada na informalidade e é de alta qualidade (DANSEREAU; GRAEN 1975; GRAEN; UHL-BIEN, 1995; LINDEN; MASLYN, 1998).

A liderança relacional traz, então, um pouco desta perspectiva da Teoria LMX, uma vez que Uhl-bien (2006) salienta a influência da relação diádica entre líder e liderado dentro de um dinamismo social. A autora propõe enxergar a liderança como um processo construtivo e contínuo. Ou seja, a liderança relacional se concentra nos processos de construção social pelos quais certos entendimentos de liderança surgem e recebem uma ontologia privilegiada. E não, como visto em outras teorias, na identificação de atributos de indivíduos envolvidos em comportamentos ou tro- cas de liderança. O termo relacional é utilizado nesta abordagem para enfatizar uma visão de liderança e de organização como construções sociais humanas, nas quais há conexões e interdependências. Aqui se percebe claramente a recursividade de Giddens: a relação líder-liderado (agentes) atua de forma recursiva (influência mútua) na organização (estrutura) em permanente construção e reconstrução no tempo.

Hunt (2004) acredita que esta compreensão da liderança está, mais do que nunca, focada em não restringir a liderança a posições ou funções hierárquicas. Em vez disso, a liderança é entendida como uma dinâmica relacional em toda a organização, em todos os níveis.

Levando em consideração o que foi descrito acima, a Teoria da Liderança Relacional pode ser analisada sob duas perspectivas: entidades e relacionamento. Ambas identificam a liderança como um processo social, porém as suas definições de processo são diferentes. A perspectiva das entidades considera que os processos são baseados nas percepções dos indivíduos quanto à troca interpessoal. Na perspectiva do relacionamento, o cerne do processo está na construção múltipla entre indivíduos e organização, uma vez que ambos não são percebidos como fabricantes do processo, mas como estando em processos. Isto é, estão em constante modificação, devido à ordem social em evolução e às possíveis mudanças no cenário organizacional - novos valores, ideologias, metas e expectativas. (UBL-BIEN, 2006).

De forma sucinta, as entidades referem-se aos indivíduos que a autora denomina como a agência individual, ou seja, "a vida organizacional é vista como resultado da ação individual” (UBL-BIEN, 2006, p. 656). Por exemplo, a organização é composta por diferentes indivíduos com saberes e conhecimentos distintos. Esses saberes e conhecimentos são vistos como propriedades de entidades. Logo, cada indivíduo que compõe a organização tem as suas percepções, orientações, intenções, personalidade, expectativas e avaliações em relação ao outro, que possui outras propriedades de entidades. Dentro desta perspectiva da entidade, Ubl-Bien (2006) afirma que a Teoria LMX é uma perspectiva centrada na entidade.

Já a perspectiva de relacionamento é fundada nas múltiplas realidades entre indivíduos e organização. Pressupõe que as realidades sociais se modificam 
e qualquer tipo de relação é tido como relação contínua, ou seja, em processo. É a maneira de perceber a liderança em processos, em que tanto o indivíduo como todo o mundo ao redor dele se relaciona de maneira influenciadora. Dessa forma, as organizações mudam de acordo com as ações das pessoas em relação umas às outras. Bem como com o ambiente socioeconômico, este também em constante mudança (ABELL; SIMONS, 2000).

Aqui vemos uma associação direta com a Teoria da Estruturação. Os agentes são capazes de se influenciar mutuamente através da dinâmica organizacional e, ao mesmo tempo, a dinâmica organizacional (a estrutura) pode modificar a relação entre os agentes (líder e liderado). A relação dos agentes com a estrutura, por outro lado, modifica continuadamente a estrutura. Dessa forma, a recursividade entre agente e estrutura fica evidente.

Tanto Giddens (2009) quanto os autores que trabalham com liderança relacional (ABELL; SIMONS, 2000; BRADBURY; LICHTENSTEIN, 2000; HOLMBERG, 2000; UBL-BIEN, 2006; 2011; KURUCZ et al., 2016; SMIT; SCHERMAN, 2016, REITZ, 2017) defendem a premissa de que a organização é uma estrutura de relações complexas e contínuas que se modificam ao longo do tempo.

A abordagem da liderança relacional se faz importante neste estudo, pois assume que a liderança decorre da interação entre os agentes (líder e liderado) e a estrutura organizacional, e vice-versa, de maneira recursiva (UHL-BIEN, 2006; KURUCZ et al., 2017). Esta compreensão a diferencia de outras abordagens de liderança. A relacional foca em como a liderança é construída, exercida, configurada e reconfigurada (SANT'ANNA et al., 2017) e não olha para os atributos individuais ou vai em busca de comportamentos eficazes.

\section{METODOLOGIA}

Para atingir o objetivo proposto neste artigo, o trabalho foi baseado na categorização de uma pesquisa qualitativa exploratória. Esse tipo de pesquisa deve ser usado quando o fenômeno pode ser mais bem observado e compreendido no contexto em que ocorre e do qual faz parte, devendo ser analisado a partir de uma perspectiva integrada (GODOY, 1995; GOLDENBERG, 2002; LAVILLE \& DIONNE, 1999). A atenção recai na relação entre indivíduos e também no local onde as práticas sociais são criadas e recriadas por eles mesmos no decorrer da vida cotidiana.

A pesquisa foi considerada como exploratória pois, apesar de existirem inúmeros estudos sobre liderança na literatura e estudos em outras áreas do conhecimento sobre a Teoria da Estruturação proposta por Giddens, é inédito um estudo em que se utiliza desses dois aportes teóricos para identificar e analisar consequências (não) premeditadas.

O estudo foi desenvolvido em uma empresa do setor de infraestrutura e tecnologia que é referência em sua área de atuação. A organização em questão, de origem brasileira, tem pouco mais de uma década de existência e conta com 32 integrantes. A unidade de análise foi escolhida por ter sido umas das empresas de um setor de prestação de serviço responsável por alavancar o PIB (Produto Interno Bruto) do país em aproximadamente $58 \%$ em um só ano.

A empresa é reconhecida nacionalmente pela sua atuação diante das gigantes estatais do setor de energia monopolizado e também por ter profissionais altamente qualificados.

A força de trabalho altamente qualificada proporcionou à pesquisa uma linha mais tênue entre líderes-liderados e menos pautada na hierarquia organizacional.

A identidade da organização e de seus empregados foi mantida em sigilo e por isso os empregadores foram denominados como E1, E2, E3 e assim consequentemente. A organização foi chamada de "empresa Alfa".

Dos 32 empregados da empresa Alfa, 10 ocupam cargo de direção. São eles: o Presidente, o Assessor da Presidência, o Diretor Administrativo e Financeiro, o Diretor Comercial e de Marketing, a Diretora de Operações e Projetos, o Chefe de Engenharia, o Diretor de Recursos Humanos, o Gerente de Controladoria, o Gerente Financeiro e o Gerente de Projetos de Tecnologia da Informação. Do total de empregados, 21 são homens e 11 são mulheres. A média de idade dos empregados que compõem a empresa Alfa é de 31 anos. A faixa etária de 16 dos 31 empregados está entre 26 e 30 anos de idade. 
Figura 2 Organograma da empresa ALFA

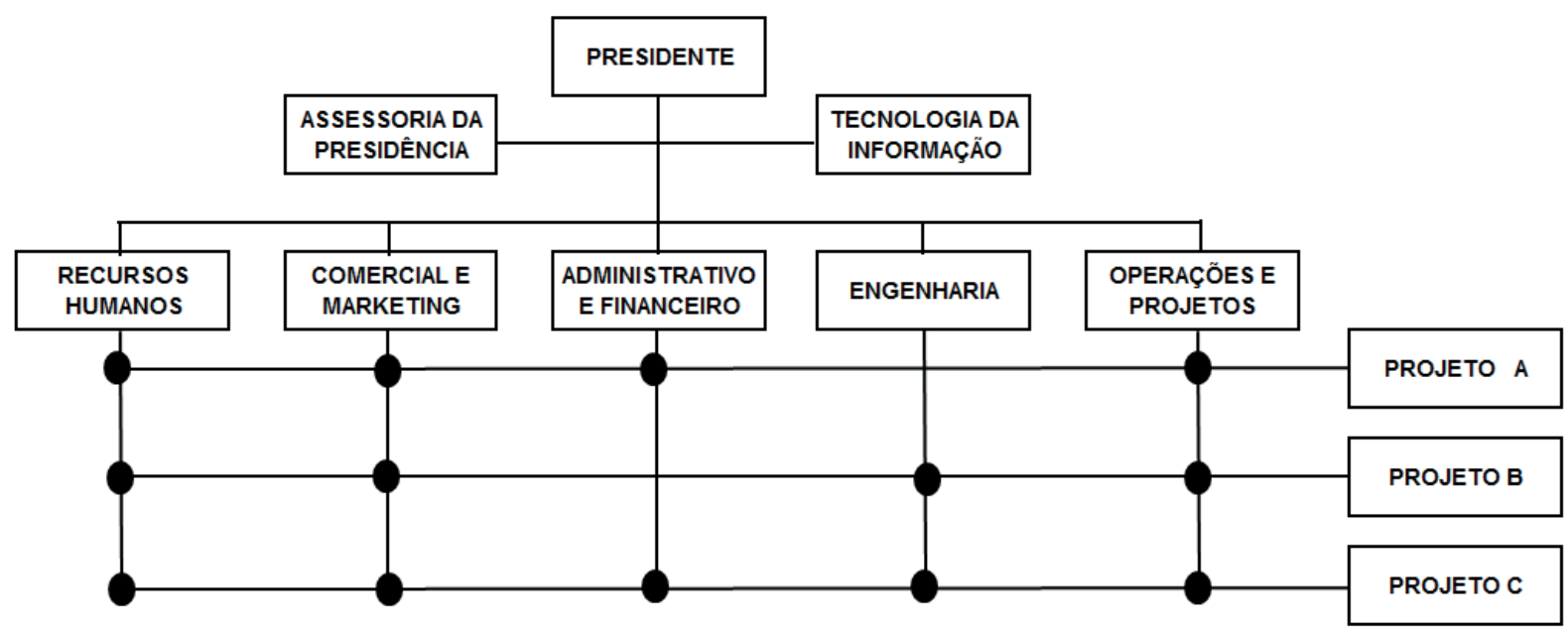

Fonte: Elaborado pelos autores

Foram utilizadas entrevistas semiestruturadas e todas foram gravadas e transcritas. Essa técnica de entrevistas foi escolhida por seu caráter de profundidade. As principais vantagens da utilização de entrevistas semiestruturadas como instrumento de coleta de dados, além da profundidade, referem-se à maior flexibilidade em permitir que tanto entrevistado quanto entrevistador tenham liberdade de discorrer livremente sobre um determinado tema, sem que sejam feitas restrições ao conteúdo e à extensão da reflexão (QUIVY; CAMPENHOUDT, 1998; YIN, 2001).

Para as entrevistas, foi utilizado um único roteiro para os 32 empregados (os 10 que ocupam cargos de gestão e os demais 22). As entrevistas foram realizadas nas dependências da empresa, em uma sala reservada para tal.

As entrevistas semiestruturadas foram realizadas em duas rodadas. Na primeira, foram coletadas informações de cargo e função, idade, tempo de empresa, estado civil, descrição da equipe e formação. Foram levados em conta aspectos da trajetória profissional, motivação para trabalhar na organização Alfa, além de questões sobre a interação entre indivíduo e estrutura e a capacidade de um interferir no outro - o que tangencia o assunto da liderança, pois grande parte dos entrevistados mencionaram os líderes como motivadores e condutores de mudanças nas organizações. Essa etapa teve duração média de 45 minutos.
O intervalo da primeira para a segunda rodada foi de 32 dias. Este foi o tempo necessário para serem avaliadas rapidamente as entrevistas da primeira rodada e serem formuladas questões que favorecessem a forma de abordar o tema da liderança no intuito de se conseguir captar a compreensão do significado da liderança para os entrevistados.

A segunda rodada versou mais profundamente sobre o tema liderança nas organizações. Foram averiguadas questões que envolvem a liderança, o discurso premeditado e as consequências não premeditadas desse discurso. Como forma de compreender o discurso e também suas limitações, foram realizadas perguntas amplas, para só então serem aprofundadas as nuances que envolvem o fenômeno da liderança. $\mathrm{Na}$ tentativa de explorar ao máximo o significado do construto para os entrevistados, foram feitas perguntas como: "O que você entende por liderança?", "Em termos de liderança no mundo, você destacaria alguém que você admira? Por quê? ”.

Em seguida, as perguntas passaram a ser mais direcionadas. Como exemplo, pode-se destacar: "Nessa empresa há alguém que você reconheça como algo próximo de ser um líder para você? Por quê?", "Em relação a seus colegas de empresa, você consegue destacar alguém que tem papel de líder para outros? Como é essa relação, ou, quais fatores proporcionam isso?". Tal direcionamento permitiu, de forma complementar, avançar no entendimento do significado dado pelos entrevistados ao construto e à percepção 
de liderança e ainda analisar as contradições próprias de tema tão complexo como a liderança. Essa etapa também teve duração média de 45 minutos.

Para interpretar e avaliar os dados coletados, foi utilizada a análise de conteúdo com a finalidade de compreender mais profundamente a percepção de liderança. Essa técnica é adequada para o trabalho de investigação de desconstrução e reconstrução dos discursos (ANGELONI, 2000; GODOY, 1995).

A categoria de análise central desta pesquisa foi denominada como mudança (no caso, organizacional). Essa categoria une a Teoria da Liderança Relacional e a Teoria da Estruturação, uma vez que ambas consideram que os indivíduos (líderes e liderados) são capazes de mudar a estrutura (organizacional) e vice-versa. Além disto, as duas teorias levam em conta que ao longo do tempo esta relação recursiva também é modificada continuadamente.

Essa categoria foi desenvolvida pelo fato de que todos os entrevistados citaram exemplos de mudanças organizacionais como fatores que exigiram novas posturas daqueles que tinham um cargo de liderança e/ou daqueles que foram escolhidos como líderes na empresa Alfa. Tais mudanças foram exemplificadas por aquelas que ocorreram tanto na empresa Alfa (empresa em que atuam) quanto em empresas de experiências profissionais anteriores. As situações mais mencionadas por esses líderes foram: 1. Experiências vividas anteriormente à empresa Alfa; 2 . Chegada do Diretor Administrativo e Financeiro (E3) na empresa Alfa; 3. A atuação do Diretor de RH (E6). As mudanças organizacionais foram discutidas ao longo da análise dos dados sob essas três situações.

A análise de conteúdo foi estruturada em três fases: a pré-análise, a exploração do material e o tratamento dos resultados. Na pré-análise, os pesquisadores obtiveram seu primeiro contato com os dados que foram submetidos à análise, assim como a definição de categorias de análise a partir desses dados (GODOY, 1995; TRIVIÑOS, 1987). A segunda fase foi marcada pela exploração do material. Nela, os documentos selecionados foram analisados e adotaram-se os procedimentos de codificação, classificação e categorização. Na terceira e última fase, ocorreram o tratamento dos resultados e a interpretação. Com suporte nos dados brutos, buscou-se categorizá-los como significativos e válidos por meio de técnicas qualitativas. Isso proporcionou a condensação de tais resultados e foi possível estabelecer padrões, tendências ou relações implícitas. Essa interpretação foi além do conteúdo aparente dos documentos, pois interessa ao pesquisador o conteúdo latente, o sentido que se encontra atrás do imediatamente expressado (BAUER et al., 2002; GODOY, 1995).

\section{MUDANÇAS ORGANIŽACIONAIS: A INFLUÊNCIA RECÍPROCA ENTRE ESTRUTURA E AGENTES, E SUAS CONSEQUÊNCIAS (NÃO) PREMEDITADAS}

A partir das entrevistas realizadas na empresa Alfa, os próprios empregados elegeram cinco pessoas as quais consideram líderes na organização: o Presidente, o Diretor Administrativo e Financeiro, a Diretora de Operações e Projetos, o Diretor de Recursos Humanos e o Analista de Engenharia mecânica. Vale ressaltar que, das 10 pessoas que ocupam cargo de direção, somente 5 foram percebidos como líderes. Portanto, quando houver referência aos líderes nesta pesquisa, está se falando destes 5 agentes. Os liderados, por sua vez, são os outros 27 funcionários. Esta proposta vai ao encontro do que Hunt e Jauch (2002) acreditam sobre a liderança relacional, uma vez que essa perspectiva não restringe a liderança a posições ou funções hierárquicas. Em vez disso, vê a liderança como uma dinâmica relacional em todos os níveis da organização.

Todos os líderes da empresa Alfa já vivenciaram situações em que foi possível destacar um agente que conseguiu mudar a forma como uma organização conquista seus resultados. As situações mais mencionadas por esses líderes foram: 1 . Experiências vividas anteriormente à empresa Alfa; 2. Chegada do Diretor Administrativo e Financeiro na empresa Alfa; 3. A atuação do Diretor de RH na empresa Alfa. Todas essas situações foram mencionadas sob o foco da resistência ou aceitação das mudanças organizacionais.

Por 4 dos 5 líderes entrevistados, foram destacadas mudanças que vieram de líderes que questionaram e colidiram com os valores e as crenças presentes na organização. Todos os líderes que vivenciaram essa 
situação foram capazes de explicar detalhadamente o ponto em que estava a organização e a maneira como o agente (o líder) mudou a forma de esta buscar seus resultados. Como exemplificado pelo entrevistado 3, que fala sobre sua percepção enquanto liderado em situação anterior de sua vida profissional:

\footnotetext{
"Já estive como gerente numa multinacional, em que o presidente pensou em mandar o diretor embora, e numa reunião que presenciei, com o ânimo já exaltado, o presidente soltou: você deveria buscar outro caminho, aqui nunca será assim. $\mathrm{O}$ diretor disse que não pediria demissão e que havia sido contratado justamente para trazer novas formas de pensar. $\mathrm{O}$ diretor ainda argumentou que se ele pelo menos tivesse a abertura para tentar implementar a linha de negócios que tanto debatera com o presidente, que se desse errado ele até pediria para sair, mas que não entregaria os pontos daquela forma [...] em outra reunião semanas depois, esse diretor teve a concessão do presidente para iniciar a linha de negócios, mas com recursos escassos. [...] Esse diretor reuniu a equipe, inclusive eu fui membro dela, e o que eu posso te falar é que ele contagiou todos, a convicção que ele tinha era algo impressionante, a vontade, os valores dele e da equipe eram de uma sintonia incrível. Ali eu vi que a mudança ocorreria [...] trabalhamos demais, muito mesmo, com muito vigor [...] menos de um ano depois nossa linha de negócios era a terceira mais representativa da empresa, [...] Esse diretor mudou de fato parte de como a organização alcança seus resultados, colocou novos valores e percepções acerca do que fazíamos lá. Não foi simplesmente a criação de valor por meio de um projeto, ele mudou a cara de uma organização quase secular. [...] Eu acho que aí depende de vários elementos como a estrutura dessa organização, se é uma organização mais aberta, se ela permite que a mudança seja catalisada por um elemento, por uma pessoa. Mas esse caso que te contei mostra claramente uma estrutura pouquíssima aberta [...]" (E3 - Diretor Administrativo e Financeiro, apontado como líder neste estudo, aqui falando na condição anterior de liderado).
}

Esse relato representa outros coletados nas entrevistas com os líderes da empresa Alfa. Uma característica comum nesses relatos é a questão da persistência e da capacidade do líder para focar no objetivo, congregar aqueles com quem trabalha e usar dos valores e das crenças que os inspiram para que colaborem e acreditem no projeto. Outra característica comum é a raridade em encontrar organizações com uma estrutura que incentive essas características em seus empregados. Na percepção dos líderes, isso exige uma maturidade organizacional fora do comum no mercado.

Dessa forma, pode-se verificar que, na concepção dos líderes entrevistados, a estrutura é importante fator que interfere decisivamente no potencial criativo e na realização desse potencial por parte dos agentes. Para eles há estruturas que favorecem as mudanças e estruturas que dificultam as mudanças. Então, desde já, pode-se dizer que, sendo fácil ou difícil, os agentes podem mudar a forma como a organização alcança seus resultados.

Apesar de os líderes entrevistados se lembrarem sempre da capacidade coercitiva da estrutura, da possibilidade de esta limitar a ação humana, eles sempre conseguiram enumerar aspectos de mudanças reais em algumas empresas por onde tiveram passagem. Por esse ponto de vista, a estrutura passa a ser também facilitadora, pois, na medida em que normaliza o comportamento humano por meio de regras e recursos, ela também proporciona a oportunidade de interação entre os agentes que, via ação social, formulam e reformulam a realidade recursivamente, em consonância com a Teoria da Estruturação.

Nesse aspecto, pode-se ressaltar ainda, para além da dualidade da estrutura, a recursividade. Em seu depoimento, o entrevistado 3 observou que o próprio Presidente da organização, naquele caso, não possibilitou inicialmente a criação da linha de negócios idealizada pelo diretor. Ao possibilitá-la, no entanto, o entrevistado comentou que tal abertura veio acompanhada de menos recursos financeiros do que tal empreendimento, a priori, necessitaria. Isso quer dizer que a estrutura pode ter limitado, de alguma forma, a efetivação do potencial criativo, pelo fato de não proporcionar os recursos necessários para a abertura da nova linha de negócios. No entanto, não o impediu o projeto, que seguiu adiante conforme fora idealizado. Ao mesmo tempo em que o agente encontrou limitações e restrições em sua vida cotidiana, foi através dessa estrutura que ele se expressou e conseguiu modificá-la, pois o projeto foi um sucesso e mudou a forma como a organização passou a buscar, pelo menos, alguma parte de seus resultados. Mais uma vez, verifica-se a dualidade da estrutura, pois, ao mesmo tempo em que limitou a ação humana, ofereceu possibilidades de transformação para os agentes.

Ainda na fala do entrevistado 3, foi possível analisar três aspectos da Teoria da Estruturação: a dualidade da estrutura, a recursividade e as consequências não premeditadas da ação: 
"E se não tivesse dado certo, qual teria sido o destino dele? $\mathrm{O}$ que eu posso falar é que deu certo, e que outros projetos tão ousados quanto aqueles ganharam novas perspectivas na organização, digamos. Ela ficou menos rígida a algumas novas ideias" (E3 - Diretor Administrativo e Financeiro, falando na condição de liderado).

O primeiro aspecto, a dualidade da estrutura, pode ser verificado a partir da pergunta retórica para aludir ao fato de que, se a nova linha de negócios não tivesse obtido sucesso, teria sido o fim da trajetória do diretor naquela empresa. Sendo esse seu destino, a mesma abertura e possibilidade de se expressar que a estrutura possibilitou seria substituída por limitação e correção, punindo severamente o erro do diretor. No entanto, o fato ocorrido foi o êxito na consecução do projeto proposto pelo diretor, o que evidenciou o caráter facilitador da estrutura. No mesmo sentido, Giddens (2003) afirma que a estrutura deve ser tratada como o meio e também como o resultado da conduta que ela recursivamente organiza (dualidade da estrutura). Dessa forma, levando em consideração a concepção de relacional de Uhl-Bien (2006), a dualidade da estrutura pode ser vista como parte do processo das construções sociais humanas, onde há conexões e interdependências.

A recursividade, por sua vez, pode ser interpretada da seguinte maneira: o fato de o diretor ter utilizado uma determinada estrutura social contribuiu para a existência e legitimação dessa estrutura, mesmo que o resultado disso seja sua modificação. Pois, foi a partir da estrutura que o diretor se expressou e conseguiu provocar mudanças. A recursividade fica evidenciada na agência do diretor, que conseguiu atingir a estrutura na forma como ela alcança seus resultados. Como consequência dessa ação, tal estrutura ficou diferente, e isso impactou outros agentes - tanto os que vivenciaram a situação, quanto os que chegaram depois, mas ainda colheram as consequências não premeditadas daquela ação que se estendeu no tempo e no espaço. Segundo o próprio entrevistado, outros agentes estão se organizando para aproveitar a "flexibilidade" adquirida por essa empresa para proporem novas ideias. Essas novas ideias podem afetar a estrutura novamente, seja deixando-a ainda mais flexível, seja deixando-a mais rígida. Essas esferas, a do agente e a da estrutura, portanto, estão inter-relacionadas a todo o momento . Resta saber se essas novas ideias terão o mesmo destino que a proposta do diretor analisada no depoimento do E3, pois essa recursividade é caracterizada por eventos inéditos e imprevisíveis, uma vez que estão sujeitos aos efeitos não previstos das consequências não premeditadas. Afinal, cada indivíduo possui suas próprias particularidades devido à sua história e influencia a estrutura por meio de suas ações que, recursivamente, são influenciadas pela estrutura (UHL-BIEN, 2006).

O terceiro fator é justamente as consequências não premeditadas da ação. O diretor, ao propor a criação de uma nova linha de negócios, tinha a intenção premeditada de executar uma ação baseada numa concepção de valor e crença a respeito de práticas realizadas por aquela multinacional. A intencionalidade do diretor terminou aí, mas sua agência não. Ao conseguir propor e realizar a proposta premeditada, ele também fez outras coisas, provocou consequências que não haviam sido premeditadas. Dentre essas ações não premeditadas, ele mostrou aos outros agentes que é possível, mesmo numa organização aparentemente fechada, produzir mudanças naquele nível. Isso, segundo o E3, culminou por fazer com que outros agentes acreditassem que vale a pena insistir em suas concepções e "forçar" a abertura da estrutura para novas ideias, tão ousadas quanto as do diretor.

A agência do diretor foi ainda maior do que ele premeditou. Ele, de fato, encorajou outros agentes e isso teve o poder de criar novos arranjos não previstos naquela organização. Como enfatiza Uhl-Bien (2006), a organização é um resultado da agencia individual. Em consonância com a Teoria da Estruturação de Giddens (2003), as ações do diretor foram dotadas de consciência e intencionalidade. Contudo, ele não tem domínio de todas as consequências de seus atos, já que algumas ou mesmo várias delas não podem ser previstas. A mesma estrutura que limitou e poderia ter continuado limitando o diretor e os outros empregados da organização, ocasionando fracasso, foi a que possibilitou o êxito na criação da nova linha de negócios. Além disso, também abriu caminho para novos projetos vindos de outros líderes, o que pode ser considerado uma consequência não premeditada daquela ação.

No entanto, os outros entrevistados destacam que a vontade de realizar mudanças muitas vezes não prosperava, e que muitos desses executivos con- 
tratados tinham trajetória curta nessas organizações. O E6 ponderou:

\begin{abstract}
"Trabalhei numa empresa que substituía a maioria dos gestores da área de vendas semestralmente com a desculpa de querer gente com um perfil de vendas diferente [...] eles queriam um perfil diferente, mas nunca mudaram o perfil das metas e cobranças" (E6 - Diretor de RH, falando na condição de liderado em uma situação anterior de sua vida profissional).
\end{abstract}

Se, por um lado, a organização reconhece a necessidade de mudanças, por outro, as regras e rotinas sedimentadas no tempo e no espaço muitas vezes dificultam o potencial para a mudança. Essa vontade de provocar mudanças é muitas vezes suprimida pela dificuldade de a organização e/ou de o novo contratado atuar na forma como essas regras e rotinas estavam estruturadas. Em outras palavras, a organização simplesmente não conseguia se estruturar de forma diferente daquela que conhecia.

Esse fenômeno ocorreu inclusive na empresa Alfa e foi o relato mais citado pelos entrevistados - a chegada do E3 na empresa Alfa e sua trajetória que possibilitou mudanças na forma como a organização alcança seus resultados (segunda situação discutida neste estudo, citada na metodologia). Foram 20 dos 32 entrevistados que citaram esse caso como exemplo de uma liderança que conseguiu mudar a forma de a organização alcançar seus resultados. Lembrando que o E3 foi um dos líderes reconhecidos pela maioria dos entrevistados, pois sua chegada na empresa Alfa causou impacto.

O Presidente da organização, com a missão de estruturar e racionalizar de forma mais consistente os processos administrativos e financeiros da empresa Alfa, captou no mercado há pouco mais de dois anos o Diretor Adm. Fin. Este foi contratado com a credencial de ser um executivo mais sênior em relação à maioria dos que lá estavam, com experiência em processos e reputação invejável no mercado. $\mathrm{O}$ E3 descreveu sua primeira impressão ao chegar à empresa Alfa:

As pessoas aqui são brilhantes, elas entendem muito do negócio, mas a maioria dos profissionais entende pouco de gestão e de processos. Inclusive por isso que me chamaram para trabalhar aqui. [...] eu tive que exercitar essa questão de passar esses ideais, esses conceitos de gestão de uma forma que não ferisse a experiência anterior desses profissionais. [...] eu poderia seguir outro caminho, poderia impor, mas achei por bem me posicionar dessa forma [...] para não perderem o ímpeto criativo. [...] é uma equipe jovem que, se for adequadamente conduzida, vai longe. [...] eu jamais poderia reter esse processo criativo, mas canalizá-lo para resultados mais concretos. " (E3 - Diretor Administrativo e Financeiro, falando na condição de líder na empresa Alfa).

Muitos relatos descreveram essa situação como emblemática, pois, ao mesmo tempo em que o E3 fora convocado por interesse da organização para estruturar seus processos, este encarou incontáveis situações em que os próprios agentes se utilizaram de regras e rotinas para resistirem e apoiarem sua agência contrária à reestruturação dos processos. $\mathrm{O}$ E28 (Analista de Projetos, liderado na empresa Alfa) relatou que "num primeiro momento a chegada do Diretor Administrativo e Financeiro foi complicada, a gente sempre fez daquela forma, porque agora ela não serve mais? Mas como é decisão lá de cima..." A E5 ponderou:

Era uma empresa com pouca visão de longo prazo, metas, nada de processo definido. A vinda do Diretor Adm. Fin. foi ótima. [...] faltava foco, não dá para atirar para todos os lados [...], mas eu sabia que convencer a turma seria difícil. Foi muita novidade para eles" (E5 - Diretora de Operações e Projetos, líder na empresa Alfa).

Conforme exposto por Giddens (2003), as regras e rotinas sedimentadas ao longo do tempo, naquela estrutura, por meio da qual os agentes se expressavam, conferiam a eles poder e coesão para lutar contra aquilo que a própria organização foi buscar no mercado e que achava necessário.

É importante suscitar essa discussão sobre o impacto dos agentes na organização em relação às novas ideias e às mudanças, pois a recursividade e a dualidade da estrutura estão ancoradas nas regras, nos recursos e também nas rotinas. Portanto, mudar a forma como a organização alcança seus resultados afeta constantemente a rotina dos agentes, o que também pode ser evidenciado no conceito da liderança relacional.

Tal atitude de rejeição pode ocorrer devido ao abalo do Sistema de Segurança Básico, conforme Giddens (2003). Até a chegada do novo Diretor Adm. Fin., os processos existentes e a rotina nas quais estes eram executados garantiam aos agentes a continuidade pacífica das relações sociais. Com a chegada 
daquele que promoveria a mudança, essas rotinas seriam fortemente impactadas, e de maneira definitiva. Isso incomodou os indivíduos por atingir seu sistema de segurança básico, pois a estabilidade foi trocada por um cenário em que não havia garantias de que as relações sociais continuariam sendo como eram.

A mudança das rotinas alimenta um sentimento de incerteza e de quebra de continuidade, uma ameaça que os próprios agentes se organizam para combater, utilizando recursivamente as regras e os recursos que têm disponíveis na estrutura para manter o status quo. Essa atitude representa, por sua vez, um fortalecimento da estrutura, pois esta depende de regularidades do comportamento humano, depende dos agentes se sujeitarem a regras e recursos para se expressarem. Esse "sujeitar" normaliza seu comportamento e suas práticas, e a evocação dessas regras, recursos e rotinas fortalece a estrutura na tentativa de impedir desvios (mudanças) desses padrões estabelecidos no tempo e no espaço. Além dessa evocação, os agentes passaram a utilizar a monitoração reflexiva da ação como forma de cobrar padrões regulares de conduta, de obter a máxima coesão dos outros agentes.

Quando foi questionado aos líderes entrevistados sobre qual seria a abertura da empresa e dos colegas de trabalho para "aceitar" formas diferentes de pensar, o conceito que Giddens utiliza para estrutura ficou ainda mais perceptível. A resistência à mudança organizacional estava arraigada na história da empresa Alfa. A atuação dos agentes foi continuamente criada e recriada pelos empregados da empresa a partir dos próprios meios pelos quais eles se expressavam - estruturas e regras sociais para resistir à mudança no início do processo. Isso quer dizer que, se por um lado, a atividade humana depende dos agentes, por outro, ela é condicionada em vários aspectos pelos meios que os próprios agentes utilizam para atuar e defender seus interesses. O entrevistado 1, o Presidente da empresa Alfa, ponderou:

O ser humano detesta mudança. Se você já sabe fazer o negócio, para que você vai fazer diferente? Todo mundo tem essa tendência, salvo raríssimas exceções. Então, as pessoas acreditam que já sabem como é que se faz, geralmente não vão propor alguma coisa diferente (Entrevistado 1 - Presidente, líder da empresa Alfa).
Muitos liderados mencionaram o fato de que houve mobilização da maioria dos empregados da empresa Alfa contra as mudanças propostas por E3. Houve forte rejeição ao novo contratado. Essa resistência foi a consequência premeditada da ação dos liderados.

Com o tempo, o desenvolvimento da estruturação dos processos administrativos e financeiros, a perspectiva da elaboração do planejamento estratégico, dentre outras atividades de responsabilidade do E3, conseguiram, gradativamente, sensibilizar outros líderes e liderados de que a atuação desse Diretor era de fato necessária à empresa, pois trazia resultados e não transmitia aos empregados a ameaça a suas rotinas, como estes acreditavam que aconteceria. Essa foi uma das consequências não premeditadas da ação dos empregados.

Dessa forma, o Diretor ter conseguido se posicionar no dia a dia de forma a não ser visto como uma ameaça, ter conseguido interagir e, de algum modo, discutir pontos que poderiam mudar na organização, foi consequência não premeditada para aqueles que inicialmente foram opositores. Foi comum encontrar no relato desses empregados menções de que gradativamente as mudanças foram ocorrendo e continuaram a ocorrer, talvez não na velocidade que gostariam. Esse poderia ser um indício da estrutura atingindo o Diretor Adm. Fin., moldando o ritmo com que as mudanças propostas por ele seriam implementadas. O E2 comentou:

\begin{abstract}
A chegada do E3 foi muito conturbada [...] foi divulgado internamente que ele estaria responsável por aprimorar muitos dos nossos "frágeis" processos; isso deixou muita gente com medo, outras com ciúmes [...] hoje ele é muito querido aqui, mas passou por tempos difíceis. (E2 - Assessor da Presidência, liderado na empresa Alfa).
\end{abstract}

Dentre os 32 entrevistados, 20 acreditam que o Diretor Administrativo e Financeiro conseguiu mudar a forma como a empresa Alfa alcança seus resultados. Dentre esses depoimentos, o mais representativo é o do E6:

O Diretor Adm. Fin. mudou a forma de alcançar os resultados dessa empresa. [...] antes a parte administrativa e financeira nem processos definidos tinha, buscávamos parceiros por meio de contatos que tínhamos da grade de relacionamento dos sócios. [...] hoje, além de termos como analisar qual 
projeto é viável, qual não é, em qual queremos apostar, [...] atualmente conseguimos parceiros. E não é por acaso, temos demonstrativos financeiros e reconhecimento no mercado que mostram nossa solidez, e isso abre uma perspectiva de mercado que simplesmente não existia aqui. (Entrevistado 6 - Diretor de RH, líder na empresa Alfa).

A questão da recursividade e da dualidade da estrutura torna-se visível. A estrutura que limitou e cerceou a atuação de E3 foi também a estrutura que ofereceu a ele a oportunidade de se expressar e de conseguir implementar mudanças, a ponto de fazer com que, em tão pouco tempo, fosse reconhecido como líder. Foi essa agência dele e dos outros que recursivamente foi moldando a estrutura e os agentes. No decorrer desse movimento surgiram consequências não previstas inicialmente, que foram configurando novos arranjos em que ambas as partes atuaram e formaram novas condições não reconhecidas da ação, dinâmica própria da dureé das práticas sociais.

À medida que o Diretor passou a ter relacionamento com alguns agentes, houve também um redimensionamento da relação desses agentes com os outros agentes da empresa Alfa, o que vai ao encontro da Teoria Relacional. Isso ficou evidente no comentário da E17:

Ficou uma situação estranha, eu me sentia constrangida. Minha antiga chefe não ia com a cara dele (E3) e eu sentia que ela me cobrava uma postura, eu sabia que ela me reprovava quando conversava de coisas da minha vida com ele. [...] eu tinha que escolher, se fosse colega dele, com certeza ela não seria mais minha colega (E17 - Analista Administrativa, liderado na empresa Alfa).

A terceira situação mencionada na metodologia foi a atuação do Diretor de RH (E6) na empresa Alfa. Quando perguntados "de um modo geral, qual você acha que é a autonomia/capacidade de uma pessoa para conseguir realizar uma mudança na forma como a organização busca atingir seus resultados? ", 14 dos 32 entrevistados citaram o E6 como um líder que conseguiu realizar mudanças. E6 conseguiu quebrar paradigmas de $\mathrm{RH}$ ao ousar trilhar um modelo muito diferente do convencional, como o método utilizado para seleção de candidatos para postos de trabalho e o plano de desenvolvimento profissional (eliminação de provas e foco na motivação do candidato):
A primeira coisa que ele me disse foi: Bom dia! Quero te convencer a ficar aqui com a gente, o que nós precisamos fazer para que isso aconteça? [...]Achei isso o máximo, postura desse tipo em empresa conceituada é raro, eu entrei querendo muito a vaga e saí de lá sonhando com ela (Entrevistado 15 liderado - Analista Administrativo).

Nas outras empresas a postura dos recrutadores era outra [...] faziam um milhão de exigências, um milhão de coisas que queriam de mim. Já aqui foi o contrário, o ponto de partida sempre foi o que eu esperava e como poderiam me ajudar (Entrevistado 12 - liderado - Analista de Tecnologia da Informação).

O relato do Diretor de RH sobre mudanças na organização se aproximou da concepção das regras e rotinas e da dualidade da estrutura proposta por Giddens:

Muitas vezes, as pessoas colocam a questão do pensar diferente, da implementação das mudanças de forma simplista [...] como se fosse apenas um jogo de competição, mas não é só isso. A mudança é um foco de tensão para todos. [...] é, em nível inconsciente, o medo do que virá pela frente, se eles vão dar conta. [...] adaptação é um processo sofrido, é um momento em que todos se sentem vulneráveis, se expõem, e ninguém sabe como vai terminar, é evidente que isso gera medo, ansiedade. É natural que todos façam algo para que as coisas não mudem. [...] o que eu posso falar é que, quando uma nova ideia chega na organização, à primeira vista sempre gera rejeição e insatisfação dos colegas. [...] cansei de ser chamado de doido varrido por colegas e depois os mesmos colegas virem até minha sala me dar os parabéns. (Entrevistado 6 - Diretor de RH).

Nesse trecho da entrevista do E6, fica clara sua capacidade discursiva de compreender, que as relações sociais estão sedimentadas em questões complexas, que residem no inconsciente do indivíduo (entidade, na concepção da Teoria Relacional de Uhl-Bien) e em suas motivações. Para E6, no mesmo sentido colocado por Giddens, a padronização e rotinização da vida social são critério fundamental para a continuidade das relações sociais, na medida em que permite mitigar a ansiedade proveniente da incerteza e perpetuar um modelo de civilidade capaz de promover continuidade. Dessa forma, é natural e compreensível que, em situações em que são propostas mudanças capazes de alterar essa dinâmica, os agentes se utilizem das regras e dos recursos como forma de inibir esse potencial criativo.

A maioria dos liderados considera já ter conseguido promover mudanças na organização, com 
contribuições decisivas na construção de processos de gestão e de produção em seus respectivos setores de atuação:

\begin{abstract}
Mudanças com coisas simples, mas são mudanças que ajudam a organização. Para você ter uma ideia do que a gente fez, nós mudamos a sala de lugar, então quem emitia nota fiscal, que ficava muito longe de quem preparava o material para sair, a gente juntou os dois fisicamente, coisas deste tipo (Entrevistada 27 liderada, Analista de Projetos).
\end{abstract}

A dualidade da estrutura permite que cada contribuição que a organização incorpora de um liderado resulte em consequências não premeditadas, que podem ser o motor de partida de mudanças na forma como a organização alcança seus resultados. Nem todos os resultados de uma mudança que reforça a sedimentação das regras e dos recursos que compõem o modelo gerencial da organização podem ser previstos.

Pequenas mudanças, agregadas, vindas de vários setores, de vários profissionais que entraram e saíram da empresa, têm poder de ir alterando aos poucos a forma como a organização alcança seus resultados. Essa mudança nem sempre é perceptível a curto prazo, e nem sempre é consciente.

\section{CONSIDERAÇÕES FINAIS}

Os agentes da empresa Alfa, tanto os líderes quanto os liderados, tiveram percepções de que são capazes de influenciar a estrutura (a organização), contribuindo para a percepção de que a liderança é um processo social, o que vem ao encontro da Teoria da Liderança Relacional. Por isso, acredita-se que esta teoria auxilia na compreensão de como as entidades (indivíduos e suas particularidades) e os relacionamentos (as múltiplas realidades entre indivíduos e organização) podem ajudar as organizações a alcançarem seus resultados, lidando com situações não previstas: as mudanças organizacionais.

Todos os cinco líderes, que foram apontados como tal pelos entrevistados, já vivenciaram situações em que foi possível destacar um agente que conseguiu mudar a forma como uma organização conquista seus resultados. Seja em experiências profissionais anteriores ou na própria empresa Alfa. Apesar de ser mais comum identificar a influência da estrutura sobre os agentes, este estudo contribui ao mostrar que os agentes são também capazes de modificar a estrutura, assim como a organização é capaz de modificar e ser modificada.

Outra contribuição deste estudo é conferir importância ao papel dos liderados, sendo estes capazes de implementar mudanças radicais, substituindo o modelo atual por novos conceitos e ideias (agente influenciando a estrutura).

Observou-se que a perspectiva das consequências não premeditadas, da recursividade, da dualidade da estrutura, das rotinas e regras expostas por Giddens e das influências mútuas entre agente e estrutura estão fortemente presentes no fenômeno da liderança. Em outras palavras, é possível associar as teorias da estruturação e da liderança relacional.

Mais um ponto de convergência deste estudo com a Teoria da Estruturação, está no fato de que a estrutura ter influenciado os líderes não significa que estes estejam sendo apenas limitados. Nada impede que os agentes se organizem para buscar outras formas de se comportarem diante da estrutura.

Portanto, esta pesquisa pode contribuir para os estudos sobre liderança, uma vez que traz a correlação entre a temática com a Teoria da Estruturação de Giddens e a Teoria da Liderança Relacional proposta por Uhl-Bien. Acredita-se que essa correlação ajuda a entender como as organizações e os indivíduos se relacionam recursivamente e como isso pode contribuir para os resultados em prol da organização.

Considera-se como limitação desta pesquisa o fato de que $1 / 3$ de seus empregados ocupe cargos gerenciais de alta qualificação, influenciando o ambiente pesquisado. Por isso, sugere-se que novas pesquisas que correlacionem as teorias aqui discutidas sejam realizadas em empresas com cenários diferentes.

\section{REFERÊNCIAS}

ABELL, E.; SIMONS, S. How much can you bend before you break: an experience of using constructionist consulting as a toll for organizational learning in the corporate world. European Journal of Work and Organizational Psycology, v. 9, n.2, p. 159-175, 2000. 
ANDERSON, H. J.; BAUR, J. E.; GRIFFITH, J. A.; BUCKLEY, M. R. What works for you may not work for (Gen)Me: Limitations of present leadership theories for the new generation. The Leadership Quarterly, v. 28, p. 245-260, 2017.

ANGELONI, M. A influência dos fatores culturais e linguísticos nas representações da decisão. Anais... EnANPAD, Rio de Janeiro, RJ, Brasil, v. $24,2000$.

BAUER, M. W., GASKELL, G.; ALLUM, N. C. Pesquisa qualitativa como texto, imagem e som: manual prático. (2a ed.). Petrópolis: Vozes, 2002.

BLAKE, R.; MOUTON, J. S. O grid gerencial. 3. ed. São Paulo: Pioneira, 1973.

BRADBURY, H.; LICHTENSTEIN, B. Relationality in organizational research: exploring the "space between". Organization Science, v. 11, n. 5, p. 551-564, 2000 .

CARVALHO NETO, A.; TANURE, B.; MOTASANTOS, M. C.; LIMA, G. S. Executivos Brasileiros: na contramão do perfil deificado da liderança transformacional. Revista de Ciências da Administração, v. 14, n.32, p. 35-49, 2012.

DAY, D.V.; FLEENOR, J.W.; ATWATER, L.E.; STURM, R.E.; MCKEE, R.A. Advances in leader and leadership development: A review of 25 years of research and theory. The Leadership Quarterly, v. 25, p. 63-82, 2014.

DINH, J. E.; LORD, R. G.; GARDNER, W. L.; MEUSER, J. D.; LIDEN, R. C.; HU, J. Leadership theory and research in the new millennium: Current theoretical trends and changing perspectives. The Leadership Quarterly, v. 25, p. 36-62, 2014.

GIDDENS, A. A Constituição da sociedade (2a ed., 3a ed.). São Paulo: Martins Fontes, 2003, 2009.
GIDDENS, A. Capitalism \& modern social theory: an analysis of the writings of Marx, Durkheim and Max Weber (15a ed.). Cambridge: Cambridge University Press, 2010.

GIDDENS, A. Política, sociologia e teoria social: encontros com o pensamento clássico e contemporâneo. São Paulo: Fundação Editora da UNESP, 1998.

GIDDENS, A. Sociologia. Porto Alegre: Artmed, 2005.

GIRARDI, D.; SOUZA, I. M.; GIRARDI, J. F. O processo de liderança e a gestão do conhecimento organizacional: as práticas das maiores indústrias catarinenses. Revista de Ciências da Administração, v. 14, n. 32, p. 65-76, 2012.

GODOY, A. Pesquisa qualitativa: tipos fundamentais. Revista de Administração de Empresas, v. 35, n.3, p. 65-71, 1995.

GOLDENBERG, M. A arte de pesquisar: como fazer pesquisa qualitativa em Ciências Sociais. Rio de Janeiro: Editora Record, 2002.

HOLMBERG, R. Organizational learning and participation: some critical reflections from a relation perspective. European Journal of Work and Organizational Psicology, v. 9, n.2, p. 177-188, 2000.

HUNT, J. G. What is leadership?. In: J. Antonakis, A. T. Cianciolo and R. J. Sternberg, Editors, The nature of leadership, Sage Publications, p. 19-48, 2004.

KURUCZ, E. et al., Relational leadership for strategic sustainability: practices and capabilities to advance the design and assessment of sustainable business models. Journal of Cleaner Production, v. 140, n. 1, p. 189-204, 2017.

LAVILLE, C.; DIONNE, J. A construção do saber: manual de metodologia da pesquisa em ciências humanas. Porto Alegre: Artes Médicas Sul Ltda, 1999. 
PERES, M. R.; PEREIRA, J. R. Teoria da estruturação forte aplicada aos estudos organizacionais. Revista de Ciências da Administração, v. 16, n. 40, p. 45$58,2014$.

QUIVY, R.; CAMPENHOUDT, L. V. Manual de Investigação em Ciências Sociais (2a ed.). Lisboa: Gradiva, 1998.

REITZ, M. Leading Questions: Dialogue in organizations: Developing relational leadership. Leadership, v. 13, n. 4, p. 516-522, 2017.

SANT'ANNA, A.; VAZ, S.; NELSON, R.; CAMPOS, M.; LEONEL, J. A. Constructivist perspective on leadership thought among Brazilian and North-American scholars. Brazilian Administration Review - BAR, v.8, p. 205-224, 2011.

SANT'ANNA, A. S.; PADILHA, L. S.; TREVISOL, M.; FILIPPIM, E. S.; BENCKE, F. F. Liderança e Sustentabilidade: Contribuições de Estudos sobre Dinâmicas Socioespaciais de Reconversão e Requalificação de Funções Econômicas. RACE: Revista de Administração, Contabilidade e Economia, v. 16, n. 3, p. 1133-1160, 2017.

SMIT, B.; SCHERMAN, V. A case for relational leadership and an ethics of care for counteracting bullying at schools. South African Journal of Education, v.36, n. 4, 2016.

SWEENEY, A.; CLARKE, N.; HIGGS, M. Shared Leadership in Commercial Organizations: A Systematic Review of Definitions, Theoretical Frameworks and Organizational Outcomes. International Journal of Management Reviews, v. 00, p. 1-22, 2018.

TRIVINOS, A. Introdução à pesquisa qualitativa em ciências sociais: a pesquisa qualitativa em educação. São Paulo: Atlas, 1987.

UHL-BIEN, M. Relational Leadership Theory: Exploring the social processes of leadership and organizing. The Leadership Quarterly. 2006.
UHL-BIEN, M.; OSPINA, S. Advancing Relational Leadership Research: A Dialogue Among Perspectives. Leadership Horizons, Greenwich: Information Age Publishing, 2012.

UHL-BIEN, M.; et al., Followership theory: A review and research agenda. The Leadership Quarterly, v. 25, n. 1, p. 83-104, 2014.

YIN, R. K. Estudo de Caso: Planejamento e Métodos. Porto Alegre: Bookman, 2001.

YULK, G.; WALL, S.; LEPSINGER, R. Preliminary report on validation of the management practices survey. In K. E. Clark \& M. B. Clark. Measures of Leadership. New Jersey: Leadership Library of America, 1990. 